\title{
Research on the Improvement Path of Teaching Quality of Public Physical Education Courses in High Schools
}

\author{
Jianing Cheng ${ }^{1}$, Renwei Jiang ${ }^{2}$, Tingyu Huo ${ }^{2}$ and Fengying Chen ${ }^{1, *}$ \\ ${ }^{1}$ School of Physical Education, China University of Geosciences, Wuhan, China \\ ${ }^{2}$ School of Art, Wuhan Sports University, Wuhan, China \\ *Corresponding author.Email:277366408@qq.com
}

\begin{abstract}
For helping college physical education to change from basic teaching to high-level teaching, from passive education to active participation, and to better use the advantages of physical education courses, this paper takes the quality of public physical education courses in colleges as a research object, and uses literature, surveys and interviews with experts to analyze the quality of courses their components, problems and improvement paths. The results found that the education quality of public physical education courses still needs to exam, currently there are still many problems in public physical education courses in colleges and universities, such as the lack of guidance when students choose courses, the low level of teachers, and the physical education course venues cannot meet the requirements and learning needs of the courses. We also propose corresponding paths to improve teaching quality, such as strengthening curriculum construction and rationalizing course objectives. We hope that through the analysis of this paper, we can improve the efficiency and quality of physical education teaching in colleges and universities, promote the all-round development of students, better realize the need of "cultivating talents for all-round development", and promote the reform and development of physical education.
\end{abstract}

Keywords: Public Physical Education; Teaching Quality; Routes

\section{INTRODUCTION}

The General Office of the CPC Central Committee and the General Office of the State Council issued the "Opinions on Strengthening and Improving School Sports Work in the New Era", which requires the continuous deepening of teaching reform and strengthening the construction of physical education curriculum. The purpose of public physical education courses in colleges and universities is designing to increase students' interest in sports, encourage them to take part in sports activities, get special skills in sports, and develop physical fitness and sportsmanship in sports. The quality of teaching in public physical education courses needs to testing, because the quality of teaching is multidimensional, dynamic, sociological and contemporary, so it depends on the surrounding human environment, the conditions of facilities and equipment in sports venues, the strength of teachers and teaching subjects, all which have an impact on the quality of the courses[1]. This paper will analyze the problems in the teaching of public physical education in colleges and universities and propose reform measures to improve the teaching quality of physical education in colleges and universities.

\section{COURSE QUALITY COMPONENTS}

The teaching and learning process is a major factor in the quality of the course, since the learning outcomes of students are relating to the degree of alignment between the achievement of teaching objectives and the teaching and learning process.

Each component and link of the teaching process may become a relevant factor affecting the quality of teaching and leading to the quality of the curriculum affect. Thus, starting from the subjective factors affecting teaching quality and taking each component of the teaching process as the object, the elements constituting the quality of the physical education curriculum can divide into: curriculum orientation, curriculum objectives, curriculum content, curriculum resources, curriculum evaluation, and curriculum implementation, and these six elements cover all the links affecting the quality of the curriculum. 


\section{PROBLEMS OF PUBLIC PHYSICAL EDUCATION CLASSES IN COLLEGES AND UNIVERSITIES}

\subsection{Unclear curriculum orientation}

In the questionnaire survey, $23.97 \%$ of the students did not know about the optional courses, which indicates that when deciding the kind of public physical education courses to offer, the school needs to refer to the school's teachers' ability, teaching venues and sports equipment resources, etc. The course selection is not based on students' needs, but more on the actual situation of the school, which is not comprehensive enough in the construction of physical education course system and value orientation, at present, China's colleges and universities At present, the physical education curriculum system in China's colleges and universities includes two modules: basic courses and public courses, and the semesters in which they offer are in freshman and sophomore years, and there are almost no physical education courses in juniors and seniors, and only graduate students majoring in physical education are continuing to study physical education courses. The value orientation of the physical education curriculum is not clear enough, with more emphasis on the physical education value of physical education itself and a clear lack of orientation in other areas[2].

\subsection{Unreasonable course objectives}

According to the cultivation goal of college education, college physical education should have the characteristics of professionalism, practicality and clarity, but as we can see from the current situation of college physical education, the cultivation goals of most colleges and universities lack their own characteristics, resulting in vague and unclear teaching goals[3]. On the other hand, the current physical education curriculum goals are largely understood as a single classroom teaching goal, which neglects the classroom physical education curriculum teaching and free movement practice, there are two main problems, one is the goal system, the explicit goals are too important, the implicit goals are not enough, the physical education curriculum construction on physical education knowledge and physical education skills are very clearly defined, but the emotional and spiritual aspects of physical education The goals are very vague, and emotional education is easily missing in the implementation of physical education curriculum goals; secondly, the physical education curriculum construction needs to be further expanded and extended in terms of specific goal areas.

\subsection{Inadequate course content}

The content of the course is the subject matter knowledge and skills learned by the students, transmitted directly to them by the teacher in the classroom, so the selection of the course content is crucial[4].Nowadays, the content and methods of physical education courses in colleges and universities lack systematization and humanism, which fail to put students' all-round development in the center and can hardly meet students' inner needs, and the course content still has the tendency of "athleticization", ignoring students' all-round development of physical and mental health, which makes college physical education lose its proper position in education[5]. Moreover, the teaching content is complicated and repetitive, most of the physical education courses in colleges and universities are set up with the purpose and fundamental task of physical exercise to achieve the standard, and the syllabus specifies the physical education items to be learned by students, which makes the physical education teaching content too much and difficult to finish within the specified hours, resulting in $28.1 \%$ of the students have difficulty in absorbing the course content, resulting in each item can only be learned by walking around, which is not effective.

\subsection{Lack of course resources and low utilization rate}

There is an unreasonable structure in the teaching team of public physical education courses. At present, many teachers engaged in teaching public physical education courses in colleges and universities are mainly young teachers with low titles, while middle-aged and older teachers, especially those with the titles of associate professor and professor, are relatively few in number and low in proportion[5]. The use of curriculum resources is narrow, $41.74 \%$ of college students think that the teaching materials lack novelty, this problem is highlighted in the use of physical education materials as the only curriculum resources some teaching materials as dogma, away from multimedia; the processing of physical education materials is rough, the use of curriculum resources lack of relevance and purpose, the depth is not enough, making the uniform requirements in physical education too heavy, not flexible enough, can not well respect the Students' foundation and individual differences[6].

\subsection{Problems with course evaluation}

Firstly, there are problems with student evaluation. When students evaluate the course, few of them read the evaluation indexes carefully, and they do not check the items hastily, so the results of course evaluation will be affected to a certain extent; secondly, there are problems with peer evaluation, which is more of a competition for interests among teachers. 
Once the teaching effect of public physical education courses lacks a reasonable evaluation system and evaluation methods, then teachers will still take the mastery of sports techniques and test scores as the main basis in their evaluation of students, schools often use students' test scores and students' evaluation scores as the standard when evaluating teachers, lacking comprehensive assessment of humanistic qualities, knowledge structure, overall teaching ability and other aspects[7].

\subsection{The essence of curriculum implementation is not reflected}

Curriculum implementation refers to the purposeful, planned and organized according to the nature of the curriculum, objectives, target content framework, evaluation recommendations, etc., as determined by the physical education and health curriculum standards, in reference to the chosen textbook is the system structure, content materials, presentation, etc., combined with the physical education teacher's own teaching quality, experience, style, from the students' learning level, aspirations, habits have been teaching the equipment, resources, environment and other conditions. The practice shows the essence of physical education and health curriculum. However, universities do not reflect its essence, i.e., realism, adaptability and creativity, in the process of curriculum implementation.

Many schools do not really consider the needs of the target orientation in the implementation of the curriculum, do not take into account the realistic factors, the opening of classes is more arbitrary, the pursuit of the professional settings of the whole and large, there is the phenomenon of "heavy setting, light construction", the curriculum is out of touch with the reform of basic education physical education curriculum[8].Influenced by the idea of competitive sports, the curriculum implementation is not sufficiently adaptable, lack of popular recreational and non-competitive sports that are compatible with the reform of the basic education physical education curriculum. Most teachers' classroom teaching is by the book and lacks innovation.

\section{THE PATH TO IMPROVE TEACHING QUALITY}

\subsection{Clarify curriculum orientation and strengthen curriculum construction}

Listen to students' voices, set up flexible physical education course content, set up physical education course content, pay attention to the main needs and individual requirements of college students, in-depth research within the students to obtain their real ideas, and select teaching content items in a targeted manner[9]. And to increase the guidance of physical education electives for students, school administration must pay attention to the selection of courses. For example, physical education teachers are convened during the preparation period to conduct meetings on the implementation of specific course selection guidance, and the activities of course selection guidance can be conducted through open classes or multimedia lectures to help students gain a preliminary understanding of the basic concepts, competition rules and characteristics of different sports. At the same time, universities should try to strengthen the construction of physical education course learning. Improving the effectiveness of physical education course learning through syllabus regulations as well as improving teaching content and building faculty teams[10].

\subsection{Rationalize course objectives}

Be sure to develop from a single physical education skill goal to a composite physical education curriculum goal, refine various macroscopic curriculum goals into practicable microscopic goals, fully demonstrate the overall goal of quality education, specifically to highlight the classification level and refinement, including four areas of development goals.

The education of the body requires students to acquire comprehensive physical development and the ability to regulate the relationship between their physical development and the environment. Mental skills education requires college students to develop the function of physical functions, students to master sports skills and develop their own athletic ability. Character education requires the function of cultivating various spirits, good mental qualities and qualities, interpersonal skills and social attitudes such as modern sports awareness and concepts among college students. Intellectual education, the function of developing individual cognition in college students, requires students to master fitness skills and other related sports science knowledge

\subsection{To improve course content}

The study found that $94.5 \%$ of teachers believe that there is a need to "optimize the content of the materials and make them more interesting.", This requires teachers to develop and apply the teaching materials reasonably and improve the content of the course from the practical point of view, according to the physical quality of college students. In the process of teaching the course, based on the comprehensive development of students' physical and mental health, and according to the traditional theory, the principle method of exercise, exercise prescription and other knowledge, some fitness and recreational elements are added, enabling students not only to reasonably adjust the amount of exercise load, but also to master the theoretical method of physical exercise. 


\subsection{To improve educational conditions and optimizing curriculum resources}

First of all, strengthen the construction of teaching team of public physical education courses. Adhere to the principle of both training and introduction, while actively introducing excellent teachers, regularly organize the existing teachers to participate in business learning and training, and continuously improve the teaching level of teachers; secondly, improve the teaching equipment and facilities of public physical education courses, universities increase financial investment, actively improve the school physical education teaching equipment according to the needs of talent training and teachers and students' exercise needs, and at the same time strengthen the daily maintenance and Thirdly, establish a correct and scientific view of optimal allocation of physical education curriculum resources, strengthen the connection between curriculum content and students' health, life and adaptation to society, pay attention to students' diversified physical education needs, form a curriculum structure that is organically linked inside and outside the classroom and inside and outside the school, and reflect the balance, comprehensiveness and selectivity of physical education curriculum structure.

\subsection{Construction of course evaluation index system}

Taking the provisions of the Outline as the premise and the spirit of the Opinions as the basis, and in accordance with the results of the analysis of the main evaluation indicators affecting the quality of public physical education courses, and to make public physical education courses more characteristic of their own, the system of secondary evaluation indicators of course quality is constructed, Consists of the teacher's ability to teach and the students' ability to perform in the classroom.

Teachers' teaching ability is mainly reflected in three aspects: teaching methods and means, teaching organisation and management, and attitude towards teaching. Teachers should be given full freedom to teach so that they can develop their own teaching characteristics. Students' classroom performance mainly includes three aspects: attitude to class, degree of sports participation, and degree of solidarity with teachers and students. In fact, students' classroom performance largely reflects the teachers' teaching ability, but also partly due to the students' own factors. Therefore, in this indicator system, teachers and students are divided into two indicators.

\subsection{The process of implementing the curriculum}

Firstly, the choice of public physical education curriculum implementation strategies should be tailored to local conditions, set the curriculum in a scientific and reasonable manner, increase non-competitive sports and courses, strive for integration and optimisation, and give full play to the unique efficacy of each course in educating people. Secondly, attention should be paid to the role of schools in the implementation of the public physical education curriculum, and the status of the humanities curriculum should be raised. In order to train qualified physical education teachers who are proficient in basic education and quality education, the physical education curriculum in China needs to be broadened to include humanities and social science courses aimed at improving the overall quality of students. Thirdly, to build a net system of physical education and health curriculum reform, the rational setting of the curriculum system is the key, and also the key to cultivating physical education talents in the new era.

\section{CONCLUSION}

Through the analysis, it is found that there are problems in the teaching of public physical education courses in colleges and universities, the six aspects of unclear course orientation, unreasonable course objectives, imperfect course content, lack of course resources and low utilization, problems in course evaluation, and the essence of course implementation are not reflected.

Through the problems of public physical education courses in general colleges and universities, the following reform proposals are put forward: strengthen the construction of courses, rationalize course objectives, improve course content, optimize course resources, build a course evaluation index system, and implement the process of course implementation, so as to help transform physical education in colleges and universities from basic teaching to high-level teaching, promote course reform, and give better play to the advantages of physical education courses.

\section{REFERENCES}

[1] Hou Jianpeng. Research on Teaching Quality Evaluation of Public Physical Education Courses in General Colleges and Universities and Countermeasures [D]. Northeast Normal University, 2012.

[2] He Zhihui. Analysis of the current situation, problems and countermeasures of physical education curriculum construction in colleges and universities[J]. Journal of Changchun College of Education, 2014, 30(13):107-108.

[3] Wang Xianfeng. Research on the problems and countermeasures in the current physical education teaching in colleges and universities [J]. Industry and Technology Forum, 2011, 10(04):213-214. 
[4] Yao Lingjie. The main problems and countermeasure thinking in teaching aerobics courses in general colleges and universities in Anhui Province [D]. Nanjing Institute of Physical Education, 2013. DOI:

CNKI:SUN:CYYT.0.2011-04-122.

[5] Chen Bing, Guo Xiaopeng, Zhang Jingjing. Problems and countermeasures of physical education general education courses in colleges and universities [J]. Western quality education, 2017, 3(17):55-56.

[6] Jiang Shuhua, Wang Shuqin. Analysis of the problems and countermeasures in the optimal allocation of physical education curriculum resources in colleges and universities [J]. Journal of Harbin Institute of Physical Education, 2008(04):114-116. DOI:

CNKI:SUN:HRTY.0.2008-04-041.

[7] Chen Bing, Guo Xiaopeng, Zhang Jingjing.

Problems and countermeasures of physical education general education courses in colleges and universities[J]. Western Quality Education, 2017, 3(17):55-56.

[8] Yang Ning. Analysis of the problems and countermeasures of the curriculum of physical education in colleges and universities[J]. Journal of Northwestern Polytechnical University (Social Science Edition), 2017, 37(02):108-110.

[9] Chao Jiawen. Research on the problems and countermeasures of physical education curriculum system in colleges and universities $[\mathrm{J}]$. New West (Theory Edition), 2012(Z5):146+152.

[10] Wu Hong. Problems and countermeasures of physical education teaching in colleges and universities [J]. Contemporary Sports Technology, 2017, $7(12): 123+125$. 